\title{
El discurso pro-minero en Argentina. Un estudio de caso a partir de la empresa minera La Alumbrera
}

\author{
o discurso pró-mineração na Argentina. Um \\ estudo de caso da mineradora La Alumbrera
}

\section{The pro-mining speech in Argentina. A case study from the mining company La Alumbrera}

Julieta Godfrid*

Instituto de Investigaciones Gino Germani

Buenos Aires / Argentina

\begin{abstract}
RESUMEN: El presente trabajo abordó las estrategias de legitimación mega-mineras en la Argentina, a partir de la construcción de un discurso prominero. Para ello, trabajamos a partir del estudio de caso de la empresa minera La Alumbrera y su estrategia comunicacional, analizando publicaciones de la revista Minera Alumbrera. Centramos nuestro análisis en reconstruir los modos en que la empresa proyecta una imagen de sí misma (ethos) (Amossy, 2000), la escena enunciativa a la que apela para hacerlo (Maingueneau, 1998) y los lugares comunes (topor) de los cuales se vale (Perelman, 1989). La Alumbrera construye en sus publicaciones un ethos pedagógico a partir de una escenografia profesoral que se orienta a legitimar sus emprendimientos en un contexto de creciente conflictividad socioambiental.
\end{abstract}

PALABRAS CLAVE: discurso pro-minero; legitimación; mega-minería; ethos pedagógico; escenografía profesoral.

RESUMO: Este artigo abordou as estratégias de legitimação da mega mineração na Argentina, desde a construção de um discurso pró-mineração. Para isso, trabalhamos a partir do estudo de caso da mineradora La Alumbrera e sua estratégia de comunicação, analisando publicações da Revista Minera Alumbrera. Concentramos nossa análise na reconstrução dos modos nos quais a empresa projeta uma imagem de si mesma (ethos) (Amossy, 2000), a cena enunciativa que apela para fazê-la (Maingueneau, 1998) e os lugares-comuns (topoi) dos quais se vale (Perelman, 1989). La Alumbrera constrói em suas publicações um ethos pedagógico a partir de uma cenografia professoral que visa a legitimar seus negócios em um contexto de crescentes conflitos socioambientais.

$\overline{\text { *julietagodfrid@hotmail.com }}$ 
PALAVRAS-CHAVE: discurso pró-mineração; legitimação; mega mineração; ethos pedagógico; cenografia professoral.

\begin{abstract}
This paper addresses the strategies to legitimize mega-mining in Argentina, from the building of a pro-mining speech. We worked on a case study of the mining company La Alumbrera and its communication strategy, analyzing the publication "Revista Minera Alumbrera". We focused our analysis on rebuilding the ways in which the company projects an image of itself (ethos) (Amossy, 2000); the enunciative scene that calls on one to do so (Maingueneau, 1998); and the commonplaces used (Perelman, 1989). Alumbrera builds an educational ethos in its publications from a professorial setting that seeks to legitimize their businesses in a context of growing socio-environmental conflicts.
\end{abstract}

KEYWORDS: pro-mining speech; legitimation; mega-mining; pedagogical ethos; professorial scenery.

\title{
1 Introducción
}

En un escenario marcado por una creciente conflictividad socioambiental que critica la actividad mega-minera, las empresas del sector han comenzado a desarrollar políticas de Responsabilidad Social Empresaria (RSE) dirigidas a legitimar su actividad. En ese marco, un conjunto de empresas mineras en la Argentina desarrollan como parte de sus políticas de RSE estrategias comunicacionales a partir de las cuales construyen un discurso pro-minero. En el presente artículo, trabajaremos a partir del estudio de caso de la empresa mega-minera La Alumbrera (Catamarca - Argentina) y su estrategia comunicacional, a partir del análisis de sus publicaciones dirigidas a las comunidades.

Concretamente nos preguntamos: ¿De qué manera La Alumbrera construye hegemonía discursiva?, ¿qué imagen construye de sí misma a través de sus publicaciones? y ¿cuáles son los recursos y los elementos a los que recurre para hacerlo? Para contestar estas preguntas, en primer lugar presentaremos teóricamente algunas nociones propias del análisis del discurso tales como ethos y escena de enunciación fundamentalmente desde la perspectiva de Amossy (2000) y Maingueneau (1998). Asimismo, articularemos dichas nociones al concepto de hegemonía discursiva propuesto por Angenot (2010) y a la clasificación de los topoi presentada por Perelman (1989). Para luego dar lugar propiamente al análisis específico, del discurso de la empresa La Alumbrera, recuperando las nociones mencionadas para pensar concretamente cuál es el ethos que construye la empresa sobre sí, y qué escenografía despliega para hacerlo. A su vez, analizaremos a qué 
moldes argumentativos (topoi) recurre para orientar su discurso y reparar la hegemonía discursiva. Este artículo forma parte de una investigación más amplia sobre el avance mega-minero en la Argentina y las estrategias de legitimación empresarias en torno a la actividad. En este marco, el trabajo que aquí se expone constituye un resultado de investigación, producto de la Tesis de Maestría en Investigación en Ciencias Sociales realizada en la Universidad de Buenos Aires. ${ }^{1}$

\section{La perspectiva teórica: la noción de ethos; escenografía y hegemonía discursiva}

Todo discurso conlleva en sí mismo la relación frente a otros discursos, lo que implica que es producto de un intercambio, explícito o implícito, con otros enunciadores, y por tanto siempre supone la existencia de otra instancia de enunciación a la cual se dirige el enunciador y respecto del cual construye su propio discurso. En este sentido, es interesante inscribir las publicaciones de Minera Alumbrera en una configuración sociohistórica particular. La empresa comienza a diseñar su estrategia comunicacional y a publicar una serie de propagandas en formato de revistas, a partir del año 2004, en un contexto de emergencia de conflictos socioambientales (Merlinsky, 2013) y de fuertes críticas a la actividad y a la empresa, por temas de contaminación ambiental. En esta línea, Barros (2002) señala que todo discurso es producto de una crítica y, por lo tanto, la condición de emergencia de un determinado enunciado supone una dislocación en las estructuras de sentido que dan forma a lo social. Este cambio estructural provoca que aquellos significados que hasta ese momento ordenaban la percepción de una determinada situación dejen de hacerlo. De esa manera, entendemos que la condición de emergencia para el discurso pro-minero es producto de la dislocación producida por la crítica socioambiental. Ante este cambio estructural puede aparecer una multiplicidad de demandas (elementos) que intentan reordenar aquello que a partir de la dislocación aparece como carente de sentido. De ahí que la condición de producción de dicho discurso sea un intento reparador y legitimador de la crítica social. Pero a su vez intenta ir más allá de la crítica

\footnotetext{
${ }^{1}$ La tesis lleva por título "Responsabilidad social empresaria y mega-minería en la Argentina. Un estudio del caso La Alumbrera y sus estrategias de legitimación en Amaicha del Valle, Tucumán". (Tesis de Maestría no publicada), Facultad de Ciencias Sociales, Universidad de Buenos Aires, Buenos Aires.
} 
y reconvertir un discurso de lo negativo por una proposición positiva, tal como es la afirmación "La minería responsable".

De esta manera, el discurso devela marcas de proximidad o de distanciamiento frente a otros discursos, ya que ningún discurso existe de manera aislada, sino que su posición se construye frente a elementos que incorporan o rechazan otros discursos. De ahí la riqueza del concepto interdiscurso que nos propone pensar un enunciado en particular en articulación con el conjunto de unidades discursivas con las cuales entra en relación (Maingueneau, 1996).

En un registro similar, Amossy (2000) utiliza el término "interdiscurso" para pensar la diseminación y circulación de elementos dóxicos en todo tipo de discursos. Frente a la idea de doxa que supone la idea de un conjunto homogéneo de ideas, saberes y valores compartidos en una época, la autora propone la idea de elementos dóxicos para poder diferenciar en capas con distintos estatus según provengan de doctrinas más articuladas o de un conjunto de nociones vagas, fluctuantes y comunes. En este sentido, la noción de elementos dóxicos debe pensarse articuladamente con la de interdiscurso, para poder ver hasta qué punto el intercambio argumentativo supone un conjunto de saberes compartidos (que sin tener una sistematicidad demasiado grande) conforman un espacio común de sentidos. Por lo que, para poder evaluar la función que desempeñan los elementos dóxicos dentro de un discurso, es necesario percibir el enunciado dentro de un conjunto de otros discursos a partir del cual se elabora. En este sentido, es interesante analizar de qué modo el discurso pro-minero desarrollado por la empresa es producto de un intercambio argumentativo con el discurso crítico de la actividad. Asimismo, es interesante analizar qué elementos dóxicos incorpora y reelabora del discurso crítico.

Aquí es fundamental entender que el discurso ofrece un determinado universo de sentido, que se construye a partir de sus elementos dóxicos, y que se presenta a través de una manera de decir que remite a su vez a una manera de ser, y que se dirige a una participación imaginaria dentro de este universo. En términos de Maingueneau (1996) nos estamos refiriendo a varios elementos: la cuestión de la "vocalidad", el ethos y la "escena de enunciación".

Maingueneau (1996) plantea que el discurso no puede aprehenderse únicamente como "voz", sino también como cuerpo de un "enunciante" situado históricamente, e inscripto en una enunciación que por una parte presupone y por la otra valida progresivamente. En este sentido, todo discurso posee una "vocalidad" especifica que le permite a aquel que escucha o que lee ese discurso reconstruir una fuente enunciativa. Este 
origen enunciativo implica una instancia subjetiva encarnada que juega un papel de garante del habla. La condición del ethos remite a la figura de ese "garante" que se apoya en un conjunto difuso de representaciones sociales valorizadas o desvalorizadas, sobre las cuales se sostiene la enunciación, ya sea escrita u oral. El ethos designa la imagen de sí mismo que construye el locutor en su propio discurso, es decir, no está dada de antemano, sino que se construye por y en el discurso. Amossy (2000) señala que la construcción de esta imagen de sí mismo no supone que el locutor se refiera explícitamente a sus cualidades y características de forma deliberada, sino que a su estilo, sus competencias lingüísticas, los recursos a los que apela. En otras palabras, las formas en las que construye su discurso, son suficientes para dar una representación de sí mismo.

El ethos es una dimensión constitutiva de la identidad de un posicionamiento discursivo, el cual ofrece una serie de "ideas" que se presentan a través de maneras de decir y que remiten también a maneras de ser, las cuales intentan promover la adhesión a un determinado universo de sentido. Por tanto, la enunciación no tiene un fin simplemente contemplativo, sino que se dirige hacia un destinatario al que quiere movilizar para llevarlo a adherir y a identificarse con cierto universo de sentido. La relación entre el enunciador de un discurso y su destinatario no está establecida de antemano, sino que es producto del contrato de lectura (VERON, 1985) que construye el mismo discurso. Lo que supone, por una parte, la construcción de cierta imagen de sí mismo, como enunciador, y a su vez, construye cierta imagen y posiciona aquel que lo lee, sus destinatarios. Por lo que entendemos que producir un discurso es no solamente brindar una representación de sí mismo y del mundo, sino que implica a su vez una forma de acción sobre el otro. Tal como señala Austin (1971) todo enunciado constituye un acto que apunta a modificar una situación, implica un hacer. Pero no se trata aquí de pensar el discurso como una suerte de estrategia de manipulación, sino como parte del dispositivo enunciativo (MAINGUENEAU, 1998). Esto implica que todo discurso establece una escena enunciativa, en la que se constituyen una serie de personajes (figura del enunciador y del destinatario), una cronografía (un momento) y una topografía (lugar), a través de la cual se interactúa y se dialoga.

Maingueneau (1998) distingue tres tipos de escenas enunciativas: englobante, genérica y escenografía. La escena englobante corresponde al tipo de discurso que le da un estatuto pragmático, literario, religioso, filosófico, etc. La escena genérica es aquella que está vinculada a un género, 
por ejemplo, el publicitario, el informativo, la guía turística, etc. Por último, la escenografía es la escena construida por el texto mismo y no está impuesta por el género, por ejemplo, una escenografía profesoral, profética, etc. La escena englobante y la escena genérica definen conjuntamente lo que se podría llamar el marco escénico del texto. Él es quien define el espacio estable en cuyo interior el enunciado adquiere sentido, el del tipo y el género discursivo. Mientras que la escenografía tiene por objeto hacer pasar a un segundo plano al marco escénico, y definir ella misma la voz y el lugar que quiere construir de sí mismo. En este sentido, la escenografía no es simplemente un contexto, ya construido independiente al discurso, sino que es justamente la enunciación, al desarrollarse, la que se esfuerza por construir progresivamente su propio dispositivo de habla.

De esta manera, Maingueneau (2007) explica que la escenografía es un proceso paradójico y circular, que representa a partir de la figura del "bucle", a través de la cual en su propio desarrollo todo discurso pretender instituir la situación que lo hace pertinente, mientras que invita a adherir a un determinado universo de sentido. En otras palabras, es este doble proceso, (donde la escenografía legitima un enunciado que debe legitimarla), estimulando a los lectores a integrar esta comunidad de creencias compartidas, a través del cual se construye junto a otros mecanismos, una hegemonía discursiva (Angenot, 2010). Dicha hegemonía implica la construcción de un discurso que genera aceptabilidad, una verosimilitud siempre precaria y contingente, sujeta a un proceso de reparación y reconstrucciones constantes. Esta verosimilitud se construye poniendo en funcionamiento un conjunto de mecanismos de regulación sobre qué se dice, cómo se dice, quién lo dice (ethos), desde donde lo dice (escenografía), estratificando grados y formas de legitimidad. Otro de los mecanismos de los que se vale la construcción de la hegemonía discursiva son los lugares comunes (topoi), que son las premisas de carácter general que permiten fundamentar los valores y las jerarquías, sobreentendidas con frecuencia, que intervienen para justificar las mayoría de las elecciones (Perelman, 1989). En otros términos, se trata de métodos de argumentación, suerte de moldes (relaciones abstractas o esquemas formales) en los cuales pueden introducirse una gran cantidad de enunciados (Amossy, 2000). Los topoi contribuyen a darle fuerza argumentativa a un enunciado, es decir, orientan el discurso en determinada dirección. Siguiendo la clasificación realizada por Perelman (1989) pueden distinguirse entre los lugares de: cantidad (algo que 
vale más por razones cuantitativas); calidad (valorización de lo distintivo); orden (lo que precede como superior a lo posterior); lo existente (preferible como hecho de lo posible); y esencia (preferible en cuanto mejor encarna una esencia).

\section{Metodología}

Para examinar los discursos y valores construidos en torno a la megaminería por parte de la empresa, se construyó un corpus de 22 números de la revista Minera Alumbrera publicada por La Alumbrera. La publicación comenzó a distribuirse a partir del año 2004, y desde entonces se ha entregado cada año, variando su nivel de periodicidad (una vez por mes o cada dos o tres meses) aunque las publicaciones no llevan fecha, solo el número de la edición.

Decidimos trabajar con la revista mencionada por una serie de razones. En primer lugar porque dicha publicación está dirigida especialmente a las comunidades con el objetivo de presentar a la empresa, su actividad y sobre todo de notificar sus políticas de Responsabilidad Social Empresaria. En segundo lugar porque es la única que se entrega mano a mano, en las distintas comunidades próximas al emprendimiento. Asimismo, dichas publicaciones tienen como público a los sectores urbanos de las cabeceras provinciales de Tucumán y Catamarca (ya que la misma se entrega de manera gratuita, respectivamente a través del diario La Gaceta y El Ancasti). En tercer lugar, nos interesa particularmente dicha publicación porque es la única que ha persistido a lo largo de los años, siendo que otras publicaciones finalizaron su edición varios años atrás, lo que permite rastrear continuidades y cambios en el largo plazo.

Para su estudio, trabajamos a partir del análisis del discurso identificando: el contrato de lectura propuesto por la revista (Verón, 1985), la imagen que la empresa construye de sí misma (el ethos) (AMOSSY, 2000); la escena de enunciación (Maingueneau, 1998) que construye el enunciado para legitimarse; y los lugares comunes (topor) a través de lo cual lo hace (PERELMAN, 1989). Con el corpus elaborado, nos focalizamos particularmente en el análisis de 10 contratapas de la revista, que podrán encontrarse en el Anexo fotográfico de esta investigación. 


\section{Análisis}

Recapitulando algunos de los elementos teóricos recién expresados, entendemos que todo discurso es producto de un intercambio con otros discursos, que puede expresarse en la forma de una dislocación, a través de la cual la crítica hace emerger nuevas preguntas y demandas para la cual determinada hegemonía discursiva no encuentra respuestas y debe comenzar su camino de reparación. En este marco, entendemos que los cuestionamientos generados a los mega-emprendimientos mineros, a partir del año 2003 en la Argentina, produjeron una dislocación en el universo de sentido que había mantenido a la actividad minera, como no cuestionada. Ante esta situación la empresa minera La Alumbrera se vio frente a la necesidad de construir una imagen de sí misma que permita contener las críticas y legitimar su actividad. En este marco, a partir del año 2004 comenzó a publicar la revista Minera Alumbrera: Acercarnos para conocernos. Vamos a repasar brevemente entonces el contexto de aparición de la publicación.

A diferencia de otros países latinoamericanos tales como Chile, Bolivia y Perú, la Argentina no cuenta con una importante tradición minera. A pesar de esto, en los últimos 15 años el país ha experimentado (junto con otros países de la región) un boom minero, que se comprueba en el crecimiento exponencial de la cantidad de emprendimientos, pasando de 18 proyectos en el 2002 a 614 en el 2011 (Secretaría de Minería de la Nación, 2012). Dentro de este crecimiento se destacan los nuevos emprendimientos de mega-minería ${ }^{2}$ cuyo desarrollo implica profundas transformaciones a nivel territorial y la aparición de un conjunto de impactos socioambientales. Entre estos nuevos emprendimientos se ubica la empresa La Alumbrera, que es el primer emprendimiento de oro y cobre que se explotan bajo la modalidad de mega-minería en la Argentina. Se ubica en el departamento de Belén, a una distancia de $400 \mathrm{~km}$ al noroeste de San Fernando del Valle de Catamarca, ciudad capital de la provincia de Catamarca. La contracara de la expansión mega-minera es la emergencia en los últimos años de conflictos socioambientales en torno a la actividad. Estos conflictos se agudizaron

\footnotetext{
${ }^{2}$ La mega-minería implica nuevos modelos de extracción de minerales en los cuales se dinamita la montaña entera, y después se obtiene el material mineral a partir de un conjunto de procesos técnicos que requieren de una gran cantidad de recursos tales como agua y energía para su separación. Estos nuevos métodos han generado grandes controversias sociotécnicas respecto de la contaminación socioambiental.
} 
especialmente, desde el año 2003, con la repercusión que adquirió a nivel nacional, el caso Esquel, ${ }^{3}$ a partir de lo cual se han ido conformando redes de resistencia a la actividad mega-minera que se organizaron alrededor del "no a la mina" (MARÍN, 2009). Una de las repercusiones más notables de la constitución de estas nuevas redes fue la sanción de leyes provinciales ${ }^{4}$ de prohibición de la mega-minería a cielo abierto y con uso de sustancias tóxicas como cianuro: Chubut (3/2003), Río Negro (7/2005), La Rioja (3/2007), Tucumán (3/2007), Mendoza (6/2007), La Pampa (9/2007) y Córdoba $(10 / 2008) .^{5}$

La multiplicación de las redes de resistencia a la actividad, junto con la promulgación de dichas leyes, permitió visualizar las críticas socioambientales a los emprendimientos mega-mineros, y logró poner en tela de juicio la legitimidad y la continuidad de los emprendimientos. En este escenario, en el año 2004 la empresa La Alumbrera comenzó a desarrollar políticas de Responsabilidad Social Empresaria (RSE), a través de las cuales intervienen activamente en las comunidades, con programas de subsidio a escuelas, actividades productivas, fomento cultural, etc. Parte de esta política de RSE implicó comenzar a publicar ese mismo año la revista cuya contratapa analizamos.

\subsection{El ethos pedagógico y la escenografía profesoral}

La presentación de la mayoría de las contratapas se organiza de la siguiente manera, en la parte superior en letra grande, clara y centrada se

\footnotetext{
${ }^{3}$ Producto de una gran movilización popular los vecinos de la localidad, lograron que el Consejo Deliberante de la localidad de Esquel (provincia de Chubut) convocase a la realización de un referéndum sobre la aceptación o el rechazo al mega-emprendimiento de extracción de oro y plata, que la empresa Meridian Gold pretendía llevar a cabo a unos $10 \mathrm{~km}$ de la localidad de Esquel. Dicho referéndum tuvo por resultado que el $81 \%$ de los votantes se expresaran en contra de la instalación del mismo (Walter, 2008). Como consecuencia de la votación, el Consejo Deliberante local prohibió la minería con cianuro en Esquel, y la Legislatura Provincial aprobó una ley de prohibición a este tipo de minería en la provincia de Chubut.

${ }^{4}$ Las leyes son de carácter provincial, dado que los recursos naturales (como los mineros) son de dominio provincial tal como lo establece el art. 124 de la Constitución Nacional (1994).

${ }^{5}$ Posteriormente algunas provincias como La Rioja y Río Negro derogaron dichas leyes de prohibición minera.
} 
puede leer "La minería está presente en todos lados". Este primer enunciado establece el contrato que sostiene al conjunto de este discurso, la presencia de la minería en todos lados es indiscutible, y a partir de allí esta idea se irá desplegando en distintas formas argumentativas. El único lugar donde se va a mencionar el término "minería" de modo explícito es en el título, luego se produce un desplazamiento a pensar la minería a través de los minerales y más concretamente a partir del cobre. Este desplazamiento encadena dos ideas de manera no explícita, que es que si los minerales son útiles para los distintos argumentos que presenta el texto, entonces lo es la actividad minera como tal. Es decir, los minerales no pueden ser utilizados si no se extraen mediante la actividad minera, de ahí que, por tanto, la utilidad que poseen los minerales se transfiera a la utilidad de la minería como tal y, en último lugar, a la empresa La Alumbrera. Los argumentos están organizados por subtítulos temáticos y acompañados respectivamente por una foto o una ilustración. Los temas que se presentan son la salud, la vestimenta, la alimentación, el elemento histórico y la cuestión de la utilidad. Estos elementos aparecen ordenados en el texto, jerarquizando las posiciones de salud, vestimenta y alimentación. Sin duda aquí pueden reconocerse las preocupaciones más urgentes dentro de cualquier comunidad, que atañen a los problemas de la vida cotidiana. Por último, en la parte inferior de las contratapas se encuentra la firma de la empresa y su dirección web. Varios ejemplos de estas contratapas pueden visualizarse en el Anexo fotográfico de este trabajo.

En la publicación minera, la empresa construye de sí misma la imagen de una corporación con grandes conocimientos sobre la minería en general, y sobre los minerales en particular, sus usos y beneficios. Pero así también muestra a su vez un vasto conocimiento sobre otras grandes áreas tales como la salud, la vestimenta, la alimentación, la historia y el sector agrario. El ethos pedagógico remite a una escena de habla en la que la empresa ocupa el lugar del saber, de tipo enciclopédico y especialista que cubre una multiplicidad de temas y conocimientos. Esta escena de habla ubica a la empresa en una relación de asimetría respecto de su auditorio, en tanto ubica en el lugar superior a la empresa que conoce y enseña sobre una diversidad de temas y a las comunidades que reciben la revista en un lugar que no posee este saber experto. Siguiendo con la clasificación de la escena enunciativa de Maingueneau (1998), la escena englobante es la publicitaria, la escena genérica es la de una revista que publicita las utilidades de los minerales. Mientras que la escenografía es la profesoral, en la cual la 
empresa minera le enseña al lector (todas aquellas comunidades que viven próximas al emprendimiento) sobre cuáles son las utilidades y las funciones de los minerales.

Tal como explica Maingueneau (2007), la escenografía tiene por objeto hacer pasar el marco escénico, que es la publicidad, al segundo plano y presentarse como una información educativa y de interés general sobre los minerales. De este modo, el lector de la publicidad se ve en una suerte de confusión al recibir la revista, en la que no queda claro en función de qué finalidad está organizada la misma. De esta manera, la confusión se produce ya que el texto se recibió primero como una revista de tipo informática y no como una publicidad de un género determinado. Pero el discurso publicitario a diferencia de otros tiene una desventaja: el solo hecho de solicitar su lectura constituye una amenaza a la cara positiva del responsable del enunciado, a la marca, ya que se expone a ser juzgado de tal o cual manera. A su vez, constituye una amenaza a las caras negativa y positiva del destinatario, a quien tienen que quitarle tiempo y dedicación, para solicitarle que se tomen el trabajo de interesarse en el enunciado publicitario (MAINGUENEAU, 2007). Por lo que, en la búsqueda por sortear estas amenazas, el discurso publicitario recurre a una vasta cantidad de recursos lingüísticos que no son específicos de un solo género discursivo. En este sentido, para orientar al lector al universo de sentido en donde "la minería está presente en todos lados", el discurso recurre a una serie de modos de decir, de topoi, que le irán dando fuerza a su argumentación. De este modo, se puede distinguir el uso de topoi de calidad, cantidad, orden y de lo existente.

Veamos entonces algunos ejemplos de la utilización del topoi de calidad en las contratapas.

El cobre es el mejor agente antibacterial, según estudios médicos. El metal es capaz de destruir el 99\% de bacterias, hongos, ácaros, y virus sobre una superficie, transcurridos 60 minutos (Revista Minera Alumbrera n. $\left.{ }^{\circ} 2\right)$.

El cobre cuenta con excelentes propiedades para producir sonidos (Revista Minera Alumbrera n. $\left.{ }^{\circ} 17\right)$.

El cobre es el mejor material para construir ollas (Revista Minera Alumbrera n. ${ }^{\circ}$ 17). 
El cobre cumple un importante papel biológico en el proceso de fotosíntesis de las plantas, aunque no forma parte de la composición de la clorofila (Revista Minera Alumbrera n. $\left.{ }^{\circ} 20\right)$.

En la actualidad el cobre juega un rol importante en los sistemas de energía alternativa (Revista Minera Alumbrera n. $\left.{ }^{\circ} 24\right)$.

Estos enunciados construyen la idea de que el mineral es un elemento de gran importancia debido a su calidad intrínseca, a partir de una serie de adjetivos calificativos de orden positivo: "mejor", "excelentes"; "importante". A su vez, esta idea le permite articular la propuesta de que, debido a su alta calidad, este elemento tiene una gran cantidad de utilizaciones posibles. De esta manera, se apela también al topoi de cantidad. Veamos algunos fragmentos:

Cada año, unas 660 toneladas de oro se utilizan en telecomunicaciones, tecnología de información, tratamientos médicos, y múltiples usos industriales. Es un componente vital de muchos dispositivos, incluyendo las computadoras, televisores, DVD, cámaras de video y teléfonos celulares (Revista Minera Alumbrera n. ${ }^{\circ} 1$ ).

El cobre es un gran conductor de la electricidad. Esta valiosa propiedad le permitió sacar "carnet" preferencial para su uso tanto en cables y líneas de alta tensión exteriores como en cableado eléctrico de interiores (Revista Minera Alumbrera n. ${ }^{\circ}$ 1).

En el transporte, la presencia del cobre es clave. Se encuentra en autos, trenes, aviones, barcos e incluso en vehículos espaciales (Revista Minera Alumbrera n. ${ }^{\circ}$ 1).

Las cañerías de cobre para gasitería, calefacción, aire acondicionado y otros usos se encuentra en el mercado en dos temples: extruido y recodico (Revista Minera Alumbrera n. ${ }^{\circ}$ 24).

Se calcula que actualmente se utilizan a nivel mundial cerca de 22.000 millones de toneladas del rojo metal (Revista Minera Alumbrera n. ${ }^{\circ}$ 24).

El tubo de cobre, por fuerte y resistencia es la mejor elección de los contratistas modernos para instalaciones hidráulicas, de calefacción y refrigeración para edificios residenciales y comerciales (Revista Minera Alumbrera n. $\left.{ }^{\circ} 34\right)$.

Estos ejemplos permiten observar el uso combinado de ambos topoi en el que se construye la formulación de que el cobre es un mineral de alta 
calidad, que se encuentra presente en una gran y heterogénea cantidad de elementos. Esta variedad de elementos pueden ser parte de la vida cotidiana (cacerolas, cartucheras, medias, celulares, cables, herrajes, autos, alimentos, calculadoras), hasta otros de mayor complejidad (aviones, usinas, energía solar, laboratorios, circuitos electrónicos, naves espaciales, etc.). Esta construcción se realiza mediante la utilización de la enumeración de los distintos elementos, el uso de las comas, las referencias numéricas, y la alusión a expresiones de volumen como "toneladas", "millones" que implican una gran cantidad. De este modo, el topoi permite establecer la idea de que si se utiliza en muchos lugares, es necesario para la vida. A su vez, la utilización del topoi de lo existente va a reforzar esta misma idea, sin embargo desde otro lugar. Pueden mencionarse algunos ejemplos como:

La compañía IBM presentó una nueva gama de estaciones de trabajo con cinco modelos basados en tecnología de cobre. Esta incrementa el rendimiento de forma considerable con respecto a los diseños tradicionales con circuitos de aluminio (Revista Minera Alumbrera n. ${ }^{\circ} 5$ ).

En la actualidad el cobre juega un rol importante en los sistemas de energía alternativa. Un ejemplo son los sistemas solares fotovoltaicos, que requieren del metal para la transmisión de corriente, conexiones a tierra y diversos componentes, debido a sus propiedades términos y eléctricas (Revista Minera Alumbrera n. ${ }^{\circ}$ 24).

Una compañía estadounidense de fibras comenzó a utilizar plata incrustada y un sistema de iones de cobre de fibra, que ofrecen una protección efectiva y permanente antibacteriana para su uso con artículos para niños o productos para mascotas (Revista Minera Alumbrera n. $\left.{ }^{\circ} 29\right)$.

Una empresa japonesa de electrónica creó una pintura, que gracias a la generación de electricidad, es capaz de eliminar los microbios. La componen partículas de zinc, cobre y se utiliza en humificadores y aires acondicionados (Revista Minera Alumbrera n. ${ }^{\circ} 31$ ).

El cobre es el único metal que tiene el reconocimiento científico como bactericida. La Agencia de Protección Ambiental de Estados Unidos así lo registró en 2008. Y aprobó más de 400 aleaciones con estas características (Revista Minera Alumbrera n. ${ }^{\circ}$ 35).

En estas líneas, se observa como el enunciador da una multiplicidad de ejemplos sobre proyectos y emprendimientos a lo largo del mundo, construyendo así la validez de la utilidad de los minerales. Aquí destacan los 
ejemplos sobre las empresas internacionales; asimismo aparecen nombres, cifras, países; fechas construyendo la idea del dato duro. También se apela directamente a expresiones que refieren a la comprobación científica de aquello que se dice. De este modo, el enunciador apela a una legitimidad construida previamente como es la del "saber internacional" y el "saber científico" para construir un enunciado creíble. Asimismo, las fotografías y las ilustraciones al margen de cada enunciado intentan constatar aquello que se dice a través de lo visual. A su vez, el enunciado se preocupa no solo por construir la idea de que los minerales como el cobre son elementos de alta calidad que sirven para una gran cantidad de usos y que hay probados ejemplos de ello a lo largo del mundo, sino también que esto ha sido así históricamente. De ahí que se apela a la utilización del topoi del orden, a través del cual se construye la idea de que el mineral ha estado presente a lo largo de la historia, y por ello es imprescindible e incuestionable. Algunos ejemplos de ello:

Arqueólogos recuperaron un trozo del sistema de canalización de agua de la Pirámide de Keops, en Egipto. La tubería de cobre estaba en perfectas condiciones después de más de 5.000 años (Revista Minera Alumbrera n. $\left.{ }^{\circ} 20\right)$.

Los egipcios utilizaban recipientes de cobre para esterilizar para lavar heridas, igual que se hizo en Europa durante la epidemia de cólera de 1850; los aztecas usaban óxido de cobre para infecciones cutáneas (Revista Minera Alumbrera n. ${ }^{\circ}$ 2).

Analicemos en profundidad algunos elementos presentes en el enunciado de la revista Minera Alumbrera n. ${ }^{\circ}$ 2. En primer lugar, aparece la cuestión del orden, de lo que vino primero y está desde siempre. De ahí que la fuerza argumentativa de que la "minería está presente en todos lados" (presente en el título de la contratapa) se construye a partir de la idea de que ha estado primero, por los siglos de los siglos. Pero no solo es parte de la historia de todos los tiempos, sino también de todas las culturas, de esta manera se mencionan "los egipcios", "Europa", "los "aztecas". A su vez, el texto no presenta en orden cronológico a los distintos acontecimientos, y de hecho presenta exclusivamente una sola fecha, construyendo la idea de que ese origen de utilización de los minerales es impreciso, no es una fecha en particular, sino más bien la idea de lo que estuvo antes, en el pasado. La idea de que es un elemento histórico que ha estado en todas las culturas 
nos remite al tema de los cuestionamientos, es decir, es un elemento que ha estado siempre y que no ha sido problematizado hasta ese momento, por lo cual es incuestionable. Por otra parte, el texto apela al relato históricocultural que ha sido aprendido en la escuela, y por tanto, se apunta en ese registro a la legitimidad propia de la institución escolar, de esta manera el discurso se inviste de esa legitimidad, de aquel lugar incuestionable del saber. La premisa es que aquello que se aprende en la escuela está bien y es, a la vez, lo que sabemos todos.

Por último, el otro elemento que aparece asociado con lo histórico es nuevamente la cuestión de la salud. Cada uno de los ejemplos históricos tiene una finalidad sanitaria, en el primer "Los egipcios utilizaban recipientes de cobre para esterilizar agua para lavar heridas", la referencia es de tipo general, no se entra en detalles particulares, por lo cual la idea destacada es que los egipcios utilizaban los minerales para la salud. De este modo, se sostiene que los minerales han sido utilizados desde los siglos de los siglos por las distintas culturas a lo largo del mundo. Y no solo esto, sino que su utilización se ha dado en áreas fundamentales del desarrollo humano, como es la salud.

Finalmente en la mayoría de las contratapas, el discurso concluye con el logo de la empresa La Alumbrera en el margen inferior, y en algunos pocos ejemplares aparece la dirección de la página web de la misma. Esto constituye la firma del texto y es la primera vez en la contratapa que aparece mencionada dicha empresa a lo largo del discurso. La firma del texto por parte de La Alumbrera supone desplazar aquello que se dice sobre la utilidad y los beneficios de la actividad minera y los minerales como un todo a la imagen de la empresa en particular.

\section{A manera de conclusión}

La empresa construye a través del discurso una imagen de sí misma, un ethos pedagógico, no sólo como especialista y como experta en temas mineros, sino de lugar del saber en general. Se ubica a sí misma en el lugar del que conoce y del que sabe, y a su auditorio en el lugar de los que tienen que aprender. De ahí que despliega una escenografía profesoral, a partir de la cual logra poner en un segundo plano la escena publicitaria, enseñando sobre las utilidades y los beneficios de los minerales y de la minería. De este modo, la escenografía profesoral ubica al lector y a la crítica social frente a la actividad minera en el lugar del que no conoce, el de la ignorancia, es decir, se critica porque no se conoce. Por lo cual, tal como explica 
Maingueneau (1998), la escenografía legitima un enunciado, que debe, a cambio, legitimarla. En este caso, el enunciado construye la escenografía profesoral en la cual las comunidades deben aprender sobre las virtudes de los minerales en general, mientras que, al mismo tiempo, legitima la minería y la empresa como tal. El enunciado orienta al lector a adherir al universo de sentido que entiende que "la minería está presente en todos lados", sin en ningún momento hacer referencia explícita a las virtudes de la empresa, y al concluir la lectura el lector va a asociar esas ventajas de los minerales en general a la minería y a la empresa que los extrae en particular. De esta manera, tal como explica Angenot (2010), el discurso de la empresa minera va imponiendo, a través de un conjunto de elementos (su estilo, la forma, los argumentos, los topoi, etc.), cierta aceptabilidad sobre la actividad minera, la cual supone instituir dentro de lo pensable y lo decible, un encadenamiento de ideas que expresan que la minería está presente en la vida cotidiana, y que por ello es útil y necesaria para el desarrollo humano. Y en segundo lugar que no solo es útil en el presente, sino que lo ha sido a lo largo de la historia de la humanidad, lo cual le confiere un carácter indiscutible. A partir de estos elementos, el discurso construye legitimidad y consenso no solo respecto a la actividad minera como tal, sino a la empresa La Alumbrera en particular. La construcción de esta legitimidad por parte de la empresa es vital para la continuidad del emprendimiento extractivo a lo largo del tiempo, en tanto le permite ampliar su poder de influencia en el territorio donde opera.

\section{Bibliografía}

AMOSSY, R. L'argumentation dans le discours. Discours politique, littérature d'idées, fiction. Paris: Nathan, 2000.

ANGENOT, M. El discurso social. Buenos Aires: Siglo XXI, 2010.

AUSTIN, J. L. Cómo hacer cosas con palabras. Buenos Aires: Paidós, 1971.

BARROS, S. Orden, democracia y estabilidad. Discurso y política en la Argentina entre 1976 y 1991. Córdoba: Alción, 2002.

FAYE, J. P. Los lenguajes totalitarios. Madrid: Taurus, 1974.

GRIMSON, A. Cultura y neoliberalismo. Buenos Aires: CLACSO, 2007.

MAINGUENEAU, D. El ethos y la voz de lo escrito. En Versión 6, Universidad Autónoma Metropolitana de México, p. 79-92, 1996.

MAINGUENEAU, D. Análisis de textos de comunicación. Buenos Aires: Nueva Visión, 1998. 
MAINGUENEAU, D. Análisis de textos de comunicación. Buenos Aires: Nueva Visión, 2007.

MARÍN, M. C. El "no a la mina" de Esquel como acontecimiento: otro mundo posible. In: SVAMPA, M.; ANTONELLI, A. (Ed.). Minería trasnacional, narrativas del desarrollo y resistencias sociales. Buenos Aires: Biblos, 2009.

MERLINSKY, G. Cartografias del conflicto ambiental en la Argentina. Buenos Aires: CLACSO, 2013.

PERLEMAN, Ch.; OLBRECHTS-TYTECA, C. Tratado de la argumentación. Madrid: Gredos, 1989.

SECRETARÍA DE MINERÍA DE LA NACIÓN. Oportunidades de inversión, 2012. Disponible en: < http://www.mineria.gob.ar/pdf/informede-gestion.pdf>. Acceso: 1 de febrero de 2016.

VERÓN, E. El análisis del 'Contrato de Lectura', un nuevo método para los estudios de posicionamiento de los soportes de los media. Les Medias: Experiences, recherches actuelles, aplications. Paris: IREP, 1985.

WALTER, M. Nuevos conflictos ambientales mineros en Argentina. El caso Esquel (2002-2003). Revista Iberoamericana de Economía Ecológica, v. 8, p. 15-28, 2008.

Data de submissão: 17/12/2015. Data de aprovação: 18/03/2016. 


\section{Anexo fotográfico}

\section{Contratapas}

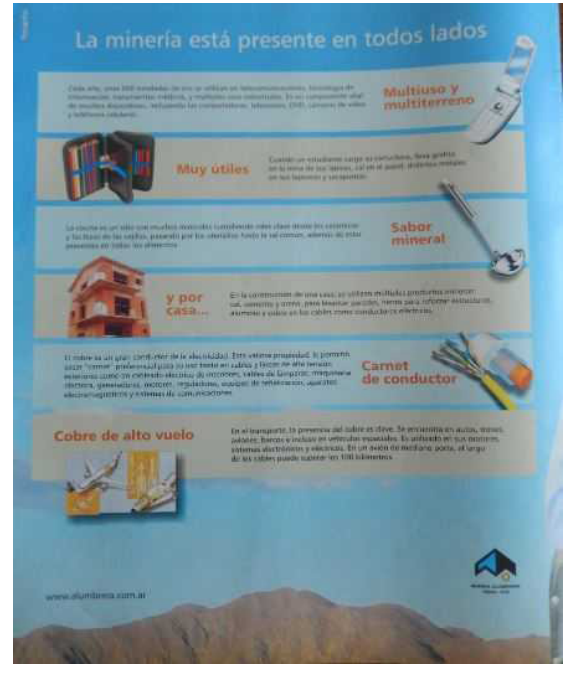

Revista Minera Alumbrera n. ${ }^{\circ} 1$

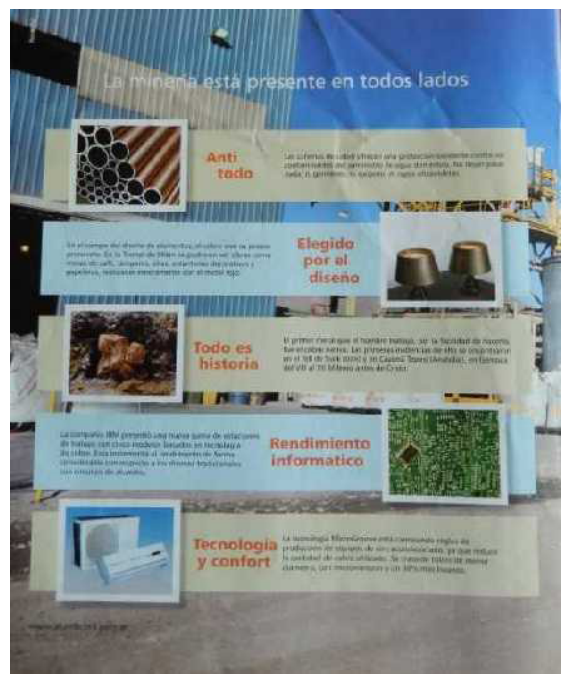

Revista Minera Alumbrera n. ${ }^{\circ} 5$

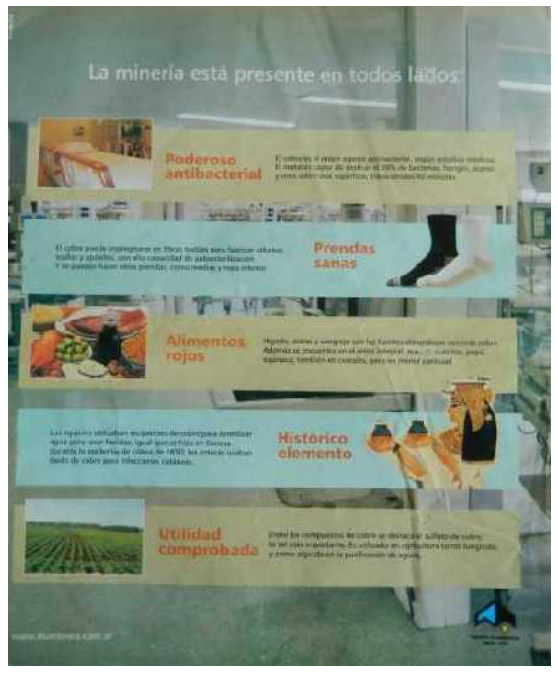

Revista Minera Alumbrera n. ${ }^{\circ} 2$

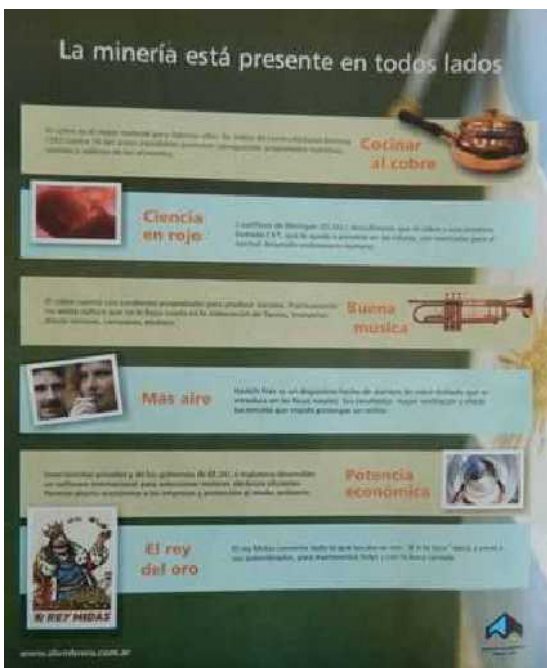

Revista Minera Alumbrera n. ${ }^{\circ} 17$ 


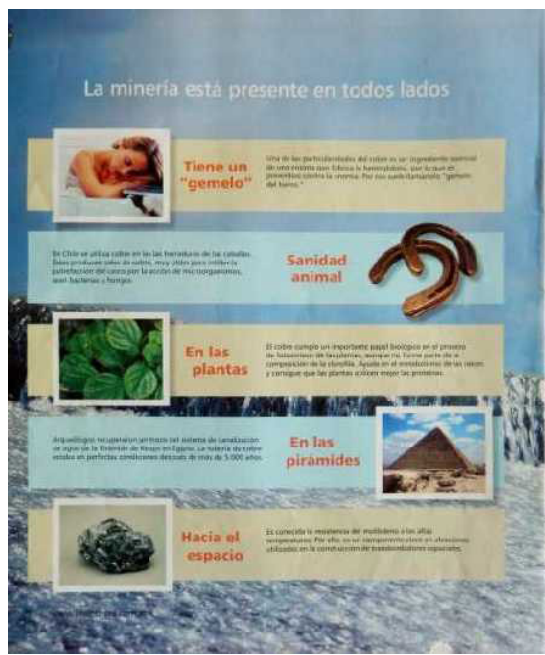

Revista Minera Alumbrera n. ${ }^{\circ} 20$

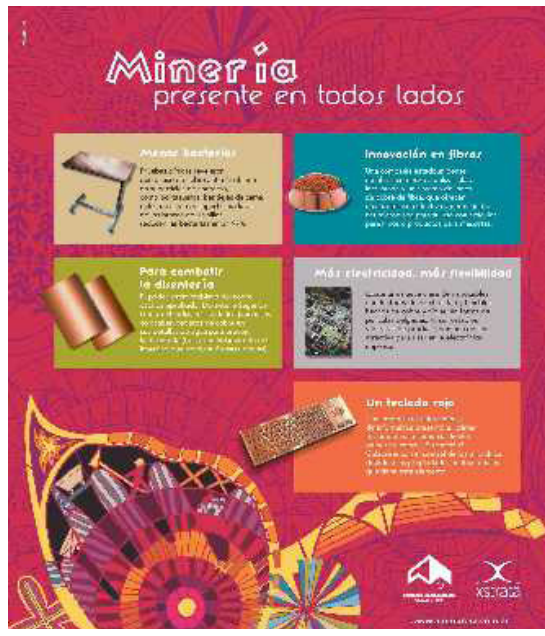

Revista Minera Alumbrera n. ${ }^{\circ} 29$

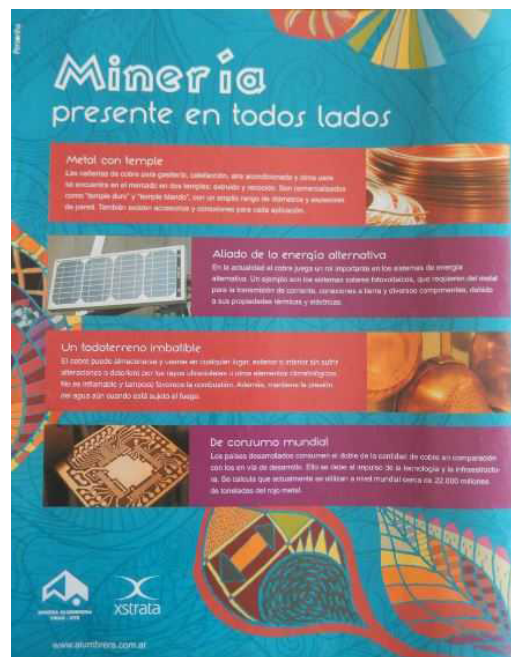

Revista Minera Alumbrera n. ${ }^{\circ} 24$

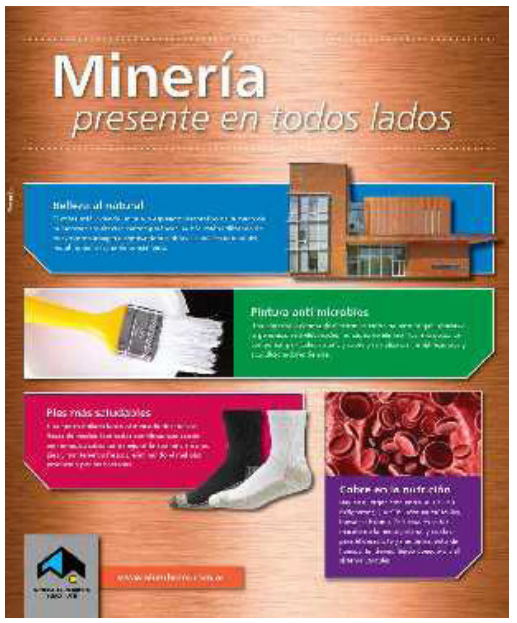

Revista Minera Alumbrera n. ${ }^{\circ} 31$ 


\section{Minería}

presente en todos lados
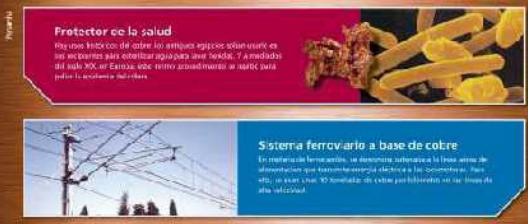

Siterra ferrcvario a base de cotre

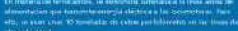
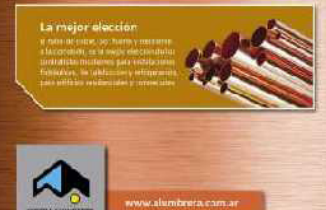

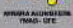

Revista Minera Alumbrera n. ${ }^{\circ} 34$

\section{Minería}

presente en todos lados
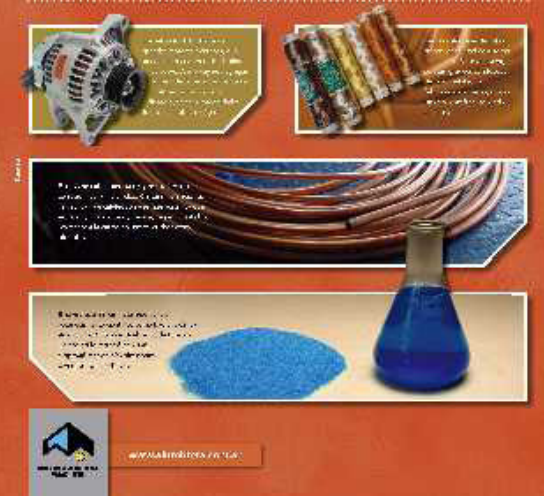

Revista Minera Alumbrera n. ${ }^{\circ} 35$ 